\title{
Evaluation of the association between coronary artery aneurysm and concomitant infection in patients with Kawasaki disease
}

Jie Liu (D 18383998@qq.com)

Guangxi Medical University First Affiliated Hospital: The First Affiliated Hospital of Guangxi Medical University https://orcid.org/0000-0002-2083-0883

SuYuan Qin

Guangxi Medical University First Affiliated Hospital: The First Affiliated Hospital of Guangxi Medical University

DanYan Su

Guangxi Medical University First Affiliated Hospital: The First Affiliated Hospital of Guangxi Medical University

BingBing Ye

Guangxi Medical University First Affiliated Hospital: The First Affiliated Hospital of Guangxi Medical University

BaoFeng Wang

Guangxi Medical University First Affiliated Hospital: The First Affiliated Hospital of Guangxi Medical University

\section{Yusheng Pang}

Guangxi Medical University First Affiliated Hospital: The First Affiliated Hospital of Guangxi Medical University

\section{Research Article}

Keywords: Kawasaki disease, concomitant infection, intravenous immunoglobulin, coronary artery aneurysm, recovery

Posted Date: March 7th, 2022

DOI: https://doi.org/10.21203/rs.3.rs-1413625/v1

License: (c) (i) This work is licensed under a Creative Commons Attribution 4.0 International License. Read Full License 


\section{Abstract}

Purpose: Multisystem inflammatory syndrome in children, which has overlapping clinical features with Kawasaki disease (KD), has generated considerable interest in the relationship between KD and infectious diseases during the ongoing global outbreak of coronavirus disease 2019. However, few studies have focused on the relationship between KD and concomitant infection, and reports on the relationship between infections and recovery from coronary artery aneurysms (CAA) are even rarer.

Methods: Patients were classified into case and control groups according to the results of their pathogen examinations, and the baseline characteristics of the two groups were compared. The Kaplan-Meier survival analysis was used to compare the medium-term recovery time of CAA between patients with and without infections, and multivariable analyses were performed to evaluate potential risk factors associated with CAA without recovery between 1 and 2 years of follow-up.

Results: A total of 353 pediatric patients with KD were included, of whom 83 (23.5\%) had confirmed co-infection. There were no significant differences in patients' response to treatment and coronary artery outcome when compared between patients with and without infections. Among the 90 patients diagnosed with CAA, 20 (22.2\%) had confirmed co-infection, and no significant differences were observed in coronary artery changes from baseline at 2 weeks, 4 weeks, and 3 months in patients with CAA with and without infections. The estimated median time (6 months, 95\%Cl:1.920-10.080) was higher in the CAA coinfected group than in the CAA non-infected group (3 months, 95\% Cl:2.366-3.634), with no significant difference. Multivariate analysis revealed that a high Zscore of the coronary artery internal diameter at 1 month after onset was significantly associated with CAA without recovery. The $Z$ score of the left main coronary artery was $\geq 3.215$ with an $89 \%$ sensitivity and $77 \%$ specificity in predicting CAA without recovery within 1 year of onset. The $Z$ score of the right coronary artery was $\geq 3.845$ with a $64 \%$ sensitivity and $98 \%$ specificity in predicting CAA without recovery within 1 year of onset and with an $83 \%$ sensitivity and $88 \%$ specificity within 2 years of onset.

Conclusions: Concomitant infection with KD diagnosis did not affect the patients' response to IVIG treatment and coronary artery outcome when compared with patients without infections; however, the time to coronary artery normalization was not notably prolonged in CAA patients with infections, but a larger maximum $Z$ score at 1 month after onset was a risk factor significantly associated with coronary artery dilatation without recovery within 2 years of onset.

\section{What Is Known}

- The etiology of Kawasaki disease (KD) may be infectious causes and is treated by intravenous immunoglobulin (IVIG).

- The coexistence of KD and infection can delay the early diagnosis and timely treatment of KD and coronary artery aneurysms (CAA).

\section{What Is New}

- Concomitant infection with KD diagnosis did not affect the patients' response to IVIG treatment and coronary artery outcome, and the time to coronary artery normalization was not notably prolonged in CAA patients with infections.

- A high Z-score of the coronary artery internal diameter at 1 month after onset was an independent predictor of CAA without recovery in patients with KD within 2 years of onset. Patients with a high Z-score of the coronary artery internal diameter may be candidates for future clinical trials of early intensification therapy with low-molecular-weight heparin or warfarin.

\section{Introduction}

During the COVID-19 pandemic, Multisystem inflammatory syndrome in children (MIS-C), which was first reported in Europe and the United States, has been considered to have a similar etiopathogenesis as Kawasaki disease (KD). MIS-C presents with overlapping clinical features with KD; further, there is a noted decrease in the incidence of KD during outbreaks due to children engaging in fewer outdoor and socializing activities [1; 2$]$. Therefore, the relationship between infections and KD has attracted renewed attention. Five decades of clues have not elucidated the etiology of KD, but may be related to the combined effects of infection, immune response, and genetic susceptibility. Most experts consider it to be the consequence of an abnormal immunological response evoked by one or more widely distributed infectious agents in genetically susceptible individuals, but conflicting studies have been published for almost all of these associations, and none have been shown to have a direct causal relationship with KD [3]. Of these, infection has long been postulated to be an important predisposing factor for KD because of its similar symptoms, marked seasonality, epidemic occurrence, and peak incidence among children aged 6 months to 2 years with relative immunodeficiency [4; 5]. Kim et al. suggested the etiological importance of antecedent infection in the development of KD [6]. To date, specific infections have been reported in patients with KD, such as Streptococcus [7], Staphylococcus aureus [8], Yersinia pseudotuberculosis [9], mycoplasma [10], Chlamydia pneumoniae [11], and measles virus [12]. Chang et al. speculated that heterogeneous infectious etiologies may be responsible for KD in different countries and during different seasons [13]. Benseler et al. [14] found that $64 \%$ of patients with KD were diagnosed with a presumptive infection before KD, most commonly tonsillitis, viral illness, pneumonia, urinary tract infection, gastroenteritis, and/or sepsis. Baker et al. [15] reported that nonspecific symptoms such as vomiting, diarrhea, abdominal pain, and cough commonly occur 10 days before the diagnosis of KD, suggesting that KD patients can have concurrent infections, and the possibility that these nonspecific symptoms result from concurrent infections unrelated to KD cannot be excluded.

As $\mathrm{KD}$ is quite similar to other infectious diseases and no specific diagnostic test is available, KD is identified on the basis of a constellation of non-specific clinical signs. The coexistence of KD and infection can delay the early diagnosis and timely treatment of KD, as well as its dreaded complication of coronary artery aneurysms (CAA) [16]. Therefore, it is crucial to closely observe nonspecific symptoms of KD and identify concurrent infections. Many studies have been conducted to accurately differentiate KD from other infectious diseases during the early phases, but few studies have examined the effect of concurrent infections on outcomes of patients with KD. The limited etiological importance of the pathogens identified so far seems to be supported by the studies of

Page $2 / 18$ 
Benseler et al.[14] Dionne et al.[17] and Jordan-Villegas et al.[18]; however, the sample size of previous studies is small and the associations have been inconsistent or not replicated, with no follow-up of the effect on infections and the recovery from CAA. This study aimed to analyze the relationship between $\mathrm{KD}$ and CAA and infections and further evaluate the potential risk factors associated with CAA without recovery with 2 years of follow-up.

\section{Materials And Methods}

Study design and population

This single-center retrospective study included children diagnosed with KD between 2012 and 2020 at the Pediatrics Department of First Affiliated Hospital of Guangxi Medical University (Nanning, China). Eligible patients were diagnosed with KD using the Diagnostic Guidelines for Kawasaki Disease (6th revision, issued by the Japan Kawasaki Disease Research Committee in 2020) [19]. CAA was defined as a coronary artery internal diameter with a Z score of $\geq 2.5$ after 1 month of the disease course according to the guidelines on the diagnosis and management of cardiovascular sequelae in Kawasaki disease (JCS/JSCS 2020) [20].

All patients were treated according to the American Heart Association guidelines [21] standard treatment protocols. Patients with IVIG resistance, defined as persistent or recrudescent fever (temperature $>38.0^{\circ} \mathrm{C}$ ) for at least 36 hours but not longer than 7 days after completion of the initial intravenous immunoglobulin (IVIG) infusion (2 g/kg), received additional rescue treatment, such as a second dose of IVIG and steroid (e.g. prednisone or methylprednisolone) therapy. All patients underwent pathogen examinations after admission, including Epstein-Barr virus (EBV), cytomegalovirus (CMV), adenovirus, rubella virus, herpes simplex virus type 2 (HSV-2), respiratory syncytial virus (RSV), parainfluenza virus [PIV] types 1, 2, and 3; influenza A and B virus nucleic acid detection; Mycoplasma pneumoniae-specific IgM (MP-IgM) antibodies, and ASO detection; and sputum and blood bacterial culture analysis. Patients with KD and CAA were classified as cases and controls, respectively, according to the results of their pathogen examinations. Cases were defined as patients with KD in whom at least one pathogen was identified, and controls were patients with KD who tested negative for those pathogens. Patient demographic characteristics, clinical presentation, laboratory results, clinical outcomes, and echocardiographic findings were compared between the groups.

The exclusion criteria included patients diagnosed with KD without IVIG treatment and diagnosed with the presence of another disease known to mimic KD, children who did not undergo pathogen examinations after admission, or those with incomplete data required for statistical analyses.

Data collection

The following clinical and laboratory data collected from the medical charts of the patients enrolled in this study were reviewed using a standardized form: (1) demographic characteristics: age, sex, height, weight, and body mass index (BMI); (2) clinical characteristics: the prevalence of incomplete KD and five principal symptoms, duration of fever before admission, illness day at treatment (illness day $1=$ first day of fever); (3) laboratory results: the highest value was selected for analysis in the case of white blood cell count (WBC), neutrophil count, aspartate aminotransferase (AST) level, alanine aminotransferase (ALT) level, total bilirubin (TSB) level, and C-reactive protein (CRP) level, whereas the lowest value was selected for hematocrit, platelet (PLT) count, serum albumin (ALB) concentration, and serum sodium concentration. All laboratory indicators were collected for assessment during the acute febrile period and prior to initial IVIG treatment. We calculated the neutrophil-to-lymphocyte count ratio, platelet-to-lymphocyte count ratio, and CRP-to-ALB ratio based on the aforementioned indicators; (4) clinical outcomes: response to IVIG treatment, incidence of pediatric intensive care unit (PICU) admission, and thrombosis; (5) we also collected data on the coronary arterial internal diameters of the right coronary artery, left main coronary artery, left anterior descending artery, and left circumflex coronary artery from echocardiography that was performed at diagnosis (before IVIG treatment), at 1 month \pm 7 days after disease onset, 3 months \pm 7 days, 6 months \pm 7 days, 1 year \pm 1 month, and 2 years \pm 1 month after disease onset. The $Z$ score of the coronary artery corrected for the body surface area was determined and recorded.

Statistical analysis

All continuous data are presented as mean \pm standard deviation or median (four-digit interval) $\left[\mathrm{P}_{50}\left(\mathrm{P}_{25}, \mathrm{P}_{75}\right)\right]$. The two-independent sample t-test, MannWhitney U test, Fisher's chi-square test, Pearson's chi-square test, and logistic regression analysis were applied to evaluate the differences between the intergroups and to determine risk factors, and the best threshold for the significant parameter was constructed using receiver operating characteristic (ROC) curves. The Kaplan-Meier survival analysis with the log-rank test was used to compare survival distributions between cohorts. The $P$-values were two-tailed with a $P<0.05$ considered statistically significant. All statistical analyses were performed using SPSS, version 26.0 (IBM Corp., Armonk, NY, USA).

\section{Results}

Comparisons between KD with and without infections

During the study period, 464 children with a diagnosis of KD were admitted to the pediatrics department of the First Affiliated Hospital of Guangxi Medical University. In total, 111 children were excluded from this study, including 35 who were treated without IVIG, 47 who did not undergo pathogen examinations after admission, and 29 with incomplete clinical or laboratory data. Ultimately, $353(76.1 \%)$ children were included in the study. Of these, 83 ( $23.5 \%)$ children had confirmed co-infections with $71(20.1 \%)$ single and 12 (3.4\%) mixed infections. The results of the analysis of KD patients co-infected by the study group are shown in the Supplementary File. There were no significant differences in patients' response to IVIG treatment and coronary artery outcomes between patients with and without infections.

Comparisons between CAA with and without infections 
Ninety hospitalized patients with KD were diagnosed with CAA. Among them, 20 (22.2\%) children had confirmed co-infections with 18 (20.0\%) single and 2 $(2.2 \%)$ mixed infections. Among the single infections, Mycoplasma hyopneumoniae $(n=10)$, adenovirus $(n=1), \operatorname{EBV}(n=1), \operatorname{RSV}(n=1), \operatorname{PIV}(n=2)$,

Staphylococcus epidermidis $(n=1)$, Stenotrophomonas maltophilia $(n=1)$, Pseudomonas aeruginosa $(n=1)$, and mixed infections included 1 mixed infection with Mycoplasma hyopneumoniae and EBV, and 1 with parainfluenza and Staphylococcus haemolyticus (Fig. 1). There were no statistically significant

differences between the CAAs with and without infections with respect to demographic, clinical characteristics, laboratory values, and clinical outcomes (all, $P$ $>0.05$ ) (Table 1). There were also no significant differences in coronary artery changes from baseline at 2 weeks, 4 weeks, and 3 months in CAA patients with and without infections (Fig. 2). The Kaplan-Meier survival analysis showed that in the co-infected group, the estimated median time (6 months, $95 \% \mathrm{Cl}$ :

0.000-19.339) was higher than that in the non-infected group ( 3 months, 95\% Cl: $1.948-4.052)$, however, the difference did not reach statistical significance (Fig. 3). 
Table 1

Comparison of baseline characteristics between coronary artery aneurysm with and without infections

\begin{tabular}{|c|c|c|c|c|}
\hline & $\begin{array}{l}\text { Total } \\
(n=90)\end{array}$ & $\begin{array}{l}\text { co-infected } \\
(n=20)\end{array}$ & $\begin{array}{l}\text { non-infected } \\
(n=70)\end{array}$ & $P$ value \\
\hline \multicolumn{5}{|l|}{ Demographic characteristics } \\
\hline Age [month, mean \pm SD] & $25.73 \pm 27.69$ & $26.10 \pm 23.64$ & $25.63 \pm 28.90$ & 0.947 \\
\hline$<1$ year $[\mathrm{n}(\%)]$ & $12(13.3)$ & $2(10.0)$ & $10(14.3)$ & 0.901 \\
\hline Male [n(\%)] & $67(74.4)$ & $13(65.0)$ & $54(77.1)$ & 0.272 \\
\hline Height $[\mathrm{m}$, mean $\pm \mathrm{SD}]$ & $0.84 \pm 0.19$ & $0.86 \pm 0.17$ & $0.84 \pm 0.20$ & 0.564 \\
\hline Weight $[\mathrm{kg}$, mean $\pm \mathrm{SD}]$ & $11.72 \pm 6.11$ & $12.15 \pm 4.53$ & $11.59 \pm 6.51$ & 0.724 \\
\hline $\mathrm{BMI}\left[\mathrm{kg} / \mathrm{m}^{2}\right.$, mean $\left.\pm \mathrm{SD}\right]$ & $15.89 \pm 1.73$ & $16.01 \pm 1.95$ & $15.86 \pm 1.68$ & 0.732 \\
\hline \multicolumn{5}{|l|}{ Clinical characteristics } \\
\hline Conjunctival injection [n(\%)] & $50(55.6)$ & $10(50.0)$ & $40(57.1)$ & 0.571 \\
\hline Changes in lips and oral cavity [n(\%)] & $46(51.1)$ & $9(45.0)$ & $37(52.9)$ & 0.535 \\
\hline Polymorphous exanthem [n(\%)] & $52(57.8)$ & $11(55.0)$ & $41(58.6)$ & 0.775 \\
\hline Cervical lymphadenopathy [n(\%)] & $33(36.7)$ & $6(30.0)$ & $27(38.6)$ & 0.483 \\
\hline Changes in extremities [n(\%)] & $28(31.1)$ & $4(20.0)$ & $24(34.3)$ & 0.224 \\
\hline Incomplete KD [n(\%)] & $30(33.3)$ & $5(25.0)$ & $25(35.7)$ & 0.370 \\
\hline $\begin{array}{l}\text { Fever duration before admission } \\
\text { [day, mean } \pm \mathrm{SD} \text { ] }\end{array}$ & $8.83 \pm 5.22$ & $9.85 \pm 5.43$ & $8.54 \pm 5.16$ & 0.326 \\
\hline $\begin{array}{l}\text { Days of illness at primary treatment } \\
\text { [day, mean } \pm S D \text { ] }\end{array}$ & $10.28 \pm 5.44$ & $10.30 \pm 3.91$ & $10.28 \pm 5.82$ & 0.986 \\
\hline$\leq 4$ days $[n(\%)]$ & $10(11.1)$ & $2(10.0)$ & $8(11.4)$ & 1.000 \\
\hline \multicolumn{5}{|l|}{ Laboratory values } \\
\hline $\begin{array}{l}\text { White blood cell count } \\
{\left[\times 10^{9} / \mathrm{L} \text {, ref. } 5-12 \times 10^{9} / \mathrm{L}\right]} \\
\text { mean } \pm \mathrm{SD}\end{array}$ & $15.59 \pm 7.76$ & $14.06 \pm 9.31$ & $16.03 \pm 7.28$ & 0.320 \\
\hline $\begin{array}{l}\text { Neutrophils count } \\
{\left[\times 10^{9} / \mathrm{L} \text {, ref. } 1.8-6.3 \times 10^{9} / \mathrm{L}\right] \text {, mean } \pm \mathrm{SD}}\end{array}$ & $9.62 \pm 6.95$ & $8.03 \pm 7.57$ & $10.08 \pm 6.75$ & 0.248 \\
\hline$\geq 80 \%[n(\%)]$ & $12(13.3)$ & $3(15.0)$ & $9(12.9)$ & 1.000 \\
\hline NLR [mean \pm SD] & $3.45 \pm 3.72$ & $2.74 \pm 3.16$ & $3.66 \pm 3.87$ & 0.335 \\
\hline Hematocrit [mean \pm SD] & $0.31 \pm 0.05$ & $0.32 \pm 0.04$ & $0.31 \pm 0.05$ & 0.457 \\
\hline $\begin{array}{l}\text { Platelet count } \\
{\left[\times 10^{12} / L \text {, ref. } 125-350 \times 10^{9} / L\right] \text {, mean } \pm S D}\end{array}$ & $396.41 \pm 211.03$ & $436.29 \pm 307.22$ & $385.02 \pm 175.68$ & 0.341 \\
\hline $\mathrm{PLR}[$ mean $\pm \mathrm{SD}]$ & $119.73 \pm 83.13$ & $110.63 \pm 59.10$ & $122.33 \pm 89.00$ & 0.582 \\
\hline $\begin{array}{l}\mathrm{CRP}[\mathrm{mg} / \mathrm{L}, \text { ref. } 0-10 \mathrm{mg} / \mathrm{L}] \\
P_{50}\left(P_{25}, P_{75}\right)\end{array}$ & $64.90(24.73,108.97)$ & $64.90(15.22,94.64)$ & $64.93(27.06,118.76)$ & 0.365 \\
\hline $\begin{array}{l}\text { Sodium } \\
\text { [mmol/L, ref. } 137-147 \mathrm{mmol} / \mathrm{L}] \text {, mean } \pm \mathrm{SD}\end{array}$ & $136.29 \pm 3.12$ & $135.65 \pm 3.36$ & $136.47 \pm 3.05$ & 0.304 \\
\hline $\begin{array}{l}A L T[U / L, \text { ref. } 7-45 U / L] \\
\text { mean } \pm S D\end{array}$ & $55.58 \pm 54.99$ & $51.50 \pm 60.24$ & $56.75 \pm 53.80$ & 0.709 \\
\hline AST [U/L, ref. $13-40 \mathrm{U} / \mathrm{L}]$, mean $\pm \mathrm{SD}$ & $56.64 \pm 74.76$ & $61.25 \pm 67.62$ & $55.33 \pm 77.08$ & 0.757 \\
\hline
\end{tabular}




\begin{tabular}{|c|c|c|c|c|}
\hline & $\begin{array}{l}\text { Total } \\
(n=90)\end{array}$ & $\begin{array}{l}\text { co-infected } \\
(n=20)\end{array}$ & $\begin{array}{l}\text { non-infected } \\
(n=70)\end{array}$ & $P$ value \\
\hline \multicolumn{5}{|l|}{$\begin{array}{l}\text { [umol/L, ref. 3.4-20.5 umol/L], } \\
\text { mean } \pm S D\end{array}$} \\
\hline Albumin $[\mathrm{g} / \mathrm{L}$, ref. $40-55 \mathrm{~g} / \mathrm{L}]$, mean $\pm \mathrm{SD}$ & $35.53 \pm 5.71$ & $34.51 \pm 5.13$ & $35.82 \pm 5.87$ & 0.367 \\
\hline CRP/ALB ratio $\left[P_{50}\left(P_{25}, P_{75}\right)\right]$ & $1.86(0.72,3.32)$ & $2.16(0.42,2.86)$ & $1.75(0.79,4.18)$ & 0.547 \\
\hline \multicolumn{5}{|l|}{ Clinical outcomes } \\
\hline PICU admission [n(\%)] & $6(6.7)$ & $1(5.0)$ & $5(7.1)$ & 1.000 \\
\hline IVIG resistance $[\mathrm{n}(\%)]$ & $20(22.2)$ & $8(40.0)$ & $12(17.1)$ & 0.062 \\
\hline Corticosteroid therapy [n(\%)] & $9(10.0)$ & $4(20.0)$ & $5(7.1)$ & 0.205 \\
\hline Thrombosis [n(\%)] & $11(12.2)$ & $4(20.0)$ & $7(10.0)$ & 0.414 \\
\hline \multicolumn{5}{|c|}{ Baseline $Z$ score of coronary artery internal diameter } \\
\hline Left main coronary artery [mean \pm SD] & $3.79 \pm 1.22$ & $3.97 \pm 1.37$ & $3.74 \pm 1.18$ & 0.456 \\
\hline Right coronary artery [mean \pm SD] & $3.39 \pm 1.39$ & $3.78 \pm 1.56$ & $3.28 \pm 1.33$ & 0.155 \\
\hline Baseline maximum $Z$ score & $4.09 \pm 1.10$ & $4.32 \pm 1.17$ & $4.02 \pm 1.08$ & 0.285 \\
\hline
\end{tabular}

Comparison between CAA with and without recovery

Among the 90 patients with CAA, follow-up data were complete for 85 patients, with 5 lost to follow-up, 57 with recovery within 1 year, and 73 within 2 years. Thrombosis developed in $12.2 \%$ (11/90) of patients, of which 10/28 (35.7\%) and 7/12 (58.3\%) had CAA without recovery after 1 year and 2 years, respectively. In both groups, the incidence of thrombosis was significantly higher than that in patients who had CAA with recovery $(P<0.001)$. The CAA without recovery group showed higher values in the platelet count, proportions of $\mathrm{HGB}<110 \mathrm{~g} / \mathrm{L}$, serum albumin level $<34 \mathrm{~g} / \mathrm{L}$, and $\mathrm{Z}$ score of coronary artery internal diameter at 1 month after onset than those of the CAA with recovery group within 1 year, and longer fever duration before admission and higher $Z$ score of coronary artery internal diameter than those of the CAA with recovery group within 2 years. No statistically significant differences were observerd between the subgroups with respect to demographic characteristics $(P>0.05)$ (Table 2). Furthermore, multivariate analysis revealed that the $Z$ score of the left main coronary artery (odds ratio, $2.054 ; 95 \% \mathrm{Cl}: 1.176-3.590$ ) and the $Z$ score of the right coronary artery (odds ratio, 2.076; 95\% Cl: 1.180-3.650) were significant independent predictors of CAA without recovery within 1 year (Table 3), but only the Z score of the right coronary artery (odds ratio, 3.072; $95 \% \mathrm{Cl}$, $1.133-$ 8.330) was a significant independent predictor of CAA without recovery within 2 years (Table 4), and this difference remained significant when corrected for age and sex. 
Table 2

Comparison of baseline characteristics between coronary artery aneurysm with and without recovery

Within 1 year

Demographic characteristics

Age [month]

$<1$ year $[\mathrm{n}(\%)]$

Male $[\mathrm{n}(\%)]$

Height $[\mathrm{m}]$

Weight $[\mathrm{kg}]$

BMI $\left[\mathrm{kg} / \mathrm{m}^{2}\right]$

Clinical characteristics

Conjunctival injection [n(\%)]

Changes in lips and oral cavity [ $\mathrm{n}(\%)]$

Polymorphous exanthem [n(\%)]

Cervical lymphadenopathy [n(\%)]

Changes in extremities $[\mathrm{n}(\%)]$

Incomplete KD [n(\%)]

Fever duration before admission [day]

Days of illness at primary treatment [day]

$\leq 4$ days $[\mathrm{n}(\%)]$

Co-infected [n(\%)]

Laboratory values

White blood cell count $\left[\times 10^{9} / L\right.$, ref. $5-$

$\left.12 \times 10^{9} / \mathrm{L}\right]$

Neutrophilscount $\left[\times 10^{9} / \mathrm{L}\right.$, ref.1.8-

$6.3 \times 10^{9} /$ L]

$\geq 80 \%[n(\%)]$

NLR

Hemoglobin [g/L, ref. $120-160 \mathrm{~g} / \mathrm{L}]$

$\leq 110 \mathrm{~g} / \mathrm{L}[\mathrm{n}(\%)]$

Platelet count $\left[\times 10^{12} / L\right.$, ref. $125-$

$\left.350 \times 10^{9} / \mathrm{L}\right]$

PLR

CRP [mg/L, ref. 0-10 mg/L]

Sodium [mmol/L, ref. $137-147 \mathrm{mmol} / \mathrm{L}$

ALT [U/L, ref. 7-45U/L]

AST [U/L, ref. 13-40U/L]

Total bilirubin [umol/L, ref. 3.4-

20.5umol/L]

Albumin [g/L, ref. $40-55 \mathrm{~g} / \mathrm{L}]$

$7.00(5.00,10.00)$ with recovery $(\mathrm{n}=$

57)

without recovery $(\mathrm{n}=$

28)

$20.00(10.50$
$32.50)$

5 (8.8)

42 (73.7)

$0.83(0.73,0.92)$

$11.34 \pm 5.28$

$15.69 \pm 1.74$

34 (59.6)

$29(50.9)$

$34(59.6)$

20 (35.1)

19 (33.3)

19 (33.3)

$9.51 \pm 4.98$

7 (12.3)

$9(15.8)$

$14.71(9.60$

19.99)

$9.10 \pm 5.94$

7 (12.3)

$3.30 \pm 3.45$

$106.57 \pm 16.13$

30 (52.6)

322.50

$(237.40,435.15)$

$110.15 \pm 86.13$

$58.75(10.45$,

114.91)

$136.14 \pm 3.03$

$50.90 \pm 53.14$

$53.85 \pm 70.78$

$8.96 \pm 15.25$

$36.04 \pm 5.76$
$14.50(8.00,34.25)$

6 (21.4)

21 (75.0)

$0.79(0.70,0.97)$

$12.80 \pm 7.89$

$16.04 \pm 1.62$

15 (53.6)

$14(50.0)$

15 (53.6)

11 (39.3)

$6(21.4)$

$9(32.1)$

$8.50(6.00,14.00)$

$11.46 \pm 6.39$

3 (10.7)

8 (28.6)

$13.29(9.31,19.94)$

$9.98 \pm 7.97$

4 (14.3)

$3.90 \pm 4.42$

$100.74 \pm 14.06$

$21(75.0)$

421.25

$(300.30,613.28)$

$141.18 \pm 81.24$

70.57 (42.31, 105.83)

$136.14 \pm 3.18$

$62.94 \pm 61.09$

$66.38 \pm 88.20$

$9.38 \pm 14.12$

$34.75 \pm 5.82$
$P$

Within 2 years

with recovery $(\mathrm{n}=$ 73) 12)

$P$

without recovery ( $\mathrm{n}=$ 


\begin{tabular}{|c|c|c|c|c|c|c|}
\hline & \multicolumn{2}{|l|}{ Within 1 year } & \multirow[t]{2}{*}{$P$} & \multicolumn{2}{|l|}{ Within 2 years } & \multirow[t]{2}{*}{$P$} \\
\hline & $\begin{array}{l}\text { with recovery }(n= \\
57)\end{array}$ & $\begin{array}{l}\text { without recovery }(n= \\
\text { 28) }\end{array}$ & & $\begin{array}{l}\text { with recovery }(n= \\
\text { 73) }\end{array}$ & $\begin{array}{l}\text { without recovery }(n= \\
\text { 12) }\end{array}$ & \\
\hline$\leq 34 \mathrm{~g} / \mathrm{L}[\mathrm{n}(\%)]$ & $16(28.1)$ & $15(53.6)$ & 0.022 & $24(32.9)$ & $7(58.3)$ & 0.169 \\
\hline CRP/ALB ratio & $2.27 \pm 2.03$ & $2.38 \pm 1.74$ & 0.795 & $2.28 \pm 1.91$ & $2.48 \pm 2.10$ & 0.734 \\
\hline \multicolumn{7}{|l|}{ Clinical outcomes } \\
\hline PICU admission [n(\%)] & $3(5.3)$ & $3(10.7)$ & 0.637 & $6(8.2)$ & $0(0.0)$ & 0.588 \\
\hline IVIG resistance [n(\%)] & $8(14.0)$ & $10(35.7)$ & 0.021 & $16(21.9)$ & $2(16.7)$ & 0.975 \\
\hline Corticosteroid therapy [n(\%)] & $2(3.5)$ & $5(17.9)$ & 0.065 & $6(8.2)$ & $1(8.3)$ & 1.000 \\
\hline Thrombosis [n(\%)] & $1(1.8)$ & $10(35.7)$ & $\begin{array}{l}< \\
0.001\end{array}$ & $4(5.5)$ & $7(58.3)$ & $\begin{array}{l}< \\
0.001\end{array}$ \\
\hline \multicolumn{7}{|c|}{ Z score of coronary artery internal diameter at 1 month after onset } \\
\hline Left main coronary artery & $2.60(2.29,3.13)$ & $4.66(3.39,5.82)$ & $<.001$ & $3.05 \pm 1.12$ & $5.58 \pm 2.06$ & $\begin{array}{l}<.001 \\
0.001\end{array}$ \\
\hline Right coronary artery & $2.13(1.48,2.83)$ & $4.68(2.79,5.65)$ & $\begin{array}{l}< \\
0.001\end{array}$ & $2.60(1.67,3.22)$ & $5.72(4.12,6.80)$ & $<.001$ \\
\hline
\end{tabular}

Table 3

Results of logistic regression analyses of coronary artery aneurysm without recovery within 1 year

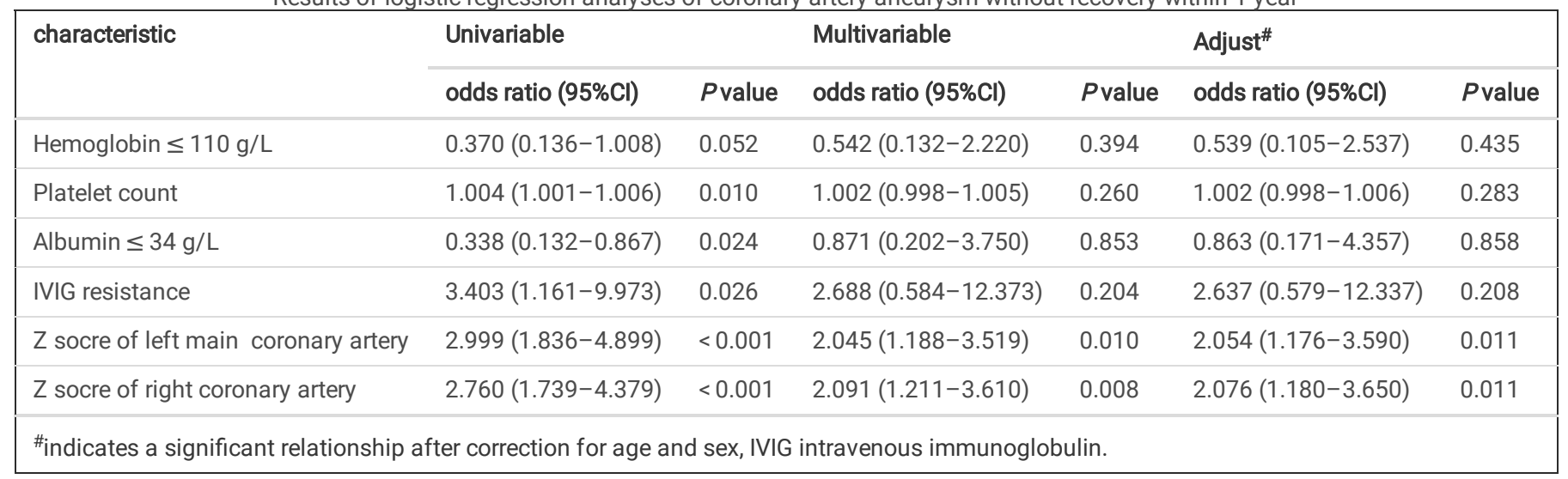

Table 4

Results of logistic regression analyses of coronary artery aneurysm without recovery within 2 years

\begin{tabular}{|c|c|c|c|c|c|c|}
\hline \multirow[t]{2}{*}{ characteristic } & \multicolumn{2}{|l|}{ Univariable } & \multicolumn{2}{|l|}{ Multivariable } & \multicolumn{2}{|l|}{ Adjust ${ }^{\#}$} \\
\hline & odds ratio $(95 \% \mathrm{Cl})$ & $P$ value & odds ratio $(95 \% \mathrm{Cl})$ & $P$ value & odds ratio $(95 \% \mathrm{Cl})$ & $P$ value \\
\hline Fever duration before admission & $1.154(1.030-1.293)$ & 0.014 & $1.136(0.962-1.343)$ & 0.133 & $1.180(0.963-1.447)$ & 0.110 \\
\hline Z socre of left main coronary artery & $3.145(1.766-5.600)$ & $<0.001$ & $2.058(0.961-4.407)$ & 0.063 & $2.212(0.962-5.086)$ & 0.062 \\
\hline Z socre of right coronary artery & $3.191(1.776-5.735)$ & $<0.001$ & $2.257(1.085-4.696)$ & 0.029 & $3.072(1.133-8.330)$ & 0.027 \\
\hline
\end{tabular}

\subsection{ROC analysis of the risk factors for CAA without recovery}

Multivariate logistic regression analysis showed that a high Z-score of the coronary artery internal diameter at 1 month after onset was significantly associated with CAA without recovery. ROC curve analysis showed that the $Z$ score of the left main coronary artery was $\geq 3.215$, with a sensitivity of $89 \%$ and specificity of $77 \%$ in predicting CAA without recovery within 1 year of onset. The Z score of the right coronary artery was $\geq 3.845$ with a sensitivity of $64 \%$ and a specificity of $98 \%$ in predicting CAA without recovery within 1 year of onset and with a sensitivity of $83 \%$ and specificity of $88 \%$ within 2 years of onset.

\section{Discussion}

The purpose of our study was to determine the effect of infections on over 300 children diagnosed with KD and to evaluate the potential risk factors associated with CAA without recovery with 2 years of follow-up. We found that concomitant infection did not affect the patients' response to IVIG treatment 
and coronary artery outcome when compared with patients without infection, and the time to coronary artery normalization was not notably prolonged for CAA patients with infections. A high Z-score of the coronary artery internal diameter at 1 month after onset was an independent predictor of CAA without recovery in patients with $\mathrm{KD}$ within 2 years of onset.

Evidence suggests that delayed therapy for KD is associated with an increased risk of treatment failure and development of CAA [22; 23], and co-infection often develops more atypical clinical presentations, leading to delayed diagnosis of KD and even worse outcomes. In our study, we found that Mycoplasma infection, which is common in preschool-aged children, constituted more than half of those infections (55.4\%), and the age of onset of KD concomitant infection may be slightly higher than those without infections, which is compatible with previous studies [24-26]. A previous study found that immune modulation of Mycoplasma infection may result in a cross-reaction between bacterial and human cell components, and auto-immunity may contribute to the pathogenesis of KD [25]. Thereafter, Park et al. [24] and Lan et al. [26] proposed that mycoplasma infections may occur simultaneously in children with KD. As symptoms of mycoplasma infection may be similar to those of KD, diagnosis may be easily missed or delayed in preschool-aged patients with $\mathrm{KD}$. A previous study identified [17] that the presence of a concomitant infection was associated with a higher rate of resistance to IVIG treatment. However, similar results were not observed in this study. Although we found a higher incidence of IVIG resistance in the co-infection KD group than in the non-infection group in our study, the difference did not reach statistical significance, and the difference in the degree of coronary artery ectasia at the 3 months follow-up also showed no significant difference between these two groups. The same finding was observed in CAA with and without infection groups, which was in agreement with the study by Benseler et al. [14], suggesting that concomitant infection did not affect the patients' response to IVIG treatment and coronary artery outcome in patients with $\mathrm{KD}$.

Long-term management and poor outcomes in KD patients with CAA have been considered serious concerns. The known risk factors for the development of CAA in patients with KD include clinical characteristics such as sex, duration of fever, and IVIG resistance [27-30]. However, our study showed no significant differences between these factors in KD patients with and without infection, and concomitant infection had little influence on the normalization of coronary artery dilatation following the acute phase, which is consistent with a previous study by Guo et al.[31]. Few studies have focused on the relationship between infections and the long-term recovery time of CAAs. In this study, we conducted a 2 years' follow-up study and found that CAA without recovery had a longer duration of fever, higher platelet count, proportion of $\mathrm{HGB}<110 \mathrm{~g} / \mathrm{L}$, serum albumin level $<34 \mathrm{~g} / \mathrm{L}$, and Z score of coronary artery internal diameter at 1 month after onset than CAA with recovery, but only the $Z$ score of coronary artery internal diameter at 1 month after onset was an independent factor for recovery of CAA in the 2 years' follow-up period. Future prospective studies with larger sample sizes are required to confirm these associations.

There is a consensus that the likelihood of coronary aneurysm regression over time was negatively correlated with the initial lesion size; giant CAAs do not revert to a normal morphology [32-35]. Studies have found that Studies have found that approximately $50 \%$ of aneurysmal coronary segments were regressed often within the first year or 2 [36], and if the coronary artery diameter in the acute phase exceeds 6 mm, the appearance of stenotic lesions and thrombosis increases significantly during the remote phase [37; 38]. Recently, researchers have advocated a Z-score adjusted for BSA for a coronary artery internal diameter to prejudge the degree of coronary artery ectasia, and several studies have reported that the likelihood of coronary artery regression within the normal range depends on the size of the baseline Z score of the coronary artery [39; 40]. One study [31] found that the left coronary artery (LCA) and LCA to aortic annulus ratio (LCA/AO) were important independent factors for coronary artery dilatation normalization. The results of the current study are comparable to those of previous studies. Our study found that aneurysmal regression occurred in $67.1 \%$ within 1 year and in $85.9 \%$ within 2 years of onset, and CAA was difficult to normalize within 1 year of onset when the $Z$ score of the left main coronary artery was $\geq 3.215$, and within 2 years of onset when the $Z$ score of the right coronary artery was $\geq 3.845$, indicating that a high $Z$ score of coronary artery internal diameter at 1 month after onset was an independent predictor of CAA without recovery in patients with KD within 2 years of onset. The present study provides evidence that the greater the CAA, the higher the risk of longer time to recovery of CAA, and the incidence of thrombosis significantly increased with increase in the recovery time.These findings could help physicians evaluate recovery time and management strategy for the surveillance and prevention of late cardiovascular events.

The present study has some limitations. First, the duration of follow-up was only 2 years, and the association between concomitant infection and long-term outcomes and coronary artery pathology in adult life is unknown. Second, this is a retrospective study, and the absence of a gold standard for KD diagnosis might have misclassified subjects, and bias might have been introduced in the results. Third, since non-routine testing and not all patients underwent coronary angiography after echocardiography, some indicators that have been reported to be associated with CAA recovery were not available in the study, such as the configuration and number of CAAs and the levels of serum tumor necrosis factor (TNF)-a and myoglobin. Finally, pathogen examinations are limited and may underestimate the prevalence of KD coinfection. This may require prospective testing in larger cohorts from different medical centers.

\title{
Conclusion
}

Concomitant infection at diagnosis of KD did not affect the patients' response to IVIG treatment and coronary artery outcome when compared with those patients without infections, and the time to coronary artery normalization was not notably prolonged for CAA patients with infections, but the $Z$ score of the coronary artery internal diameter at 1 month after onset was negatively correlated with the chance for the normalization of coronary artery dilatation within two years of onset. Patients with a high Z-score of the coronary artery internal diameter may be candidates for future clinical trials of early intensification therapy with low-molecular-weight heparin or warfarin.

\section{Abbreviations}

\author{
ALB: serum albumin
}

ALT: alanine aminotransferase

AST: aspartate aminotransferase 
BMI: body mass index

CAA: coronary artery aneurysms

CMV: cytomegalovirus

CRP: C-reactive protein

EBV: Epstein-Barr virus

HSV-2: herpes simplex virus type 2

IVIG: intravenous immunoglobulin

KD: Kawasaki disease

MIS-C: Multisystem inflammatory syndrome in children

LCA: left coronary artery

LCA/AO: LCA to aortic annulus ratio

MP-IgM: Mycoplasma pneumoniae-specific IgM

PICU: pediatric intensive care unit

PIV: parainfluenza virus

PLT: platelet

ROC: receiver operating characteristic

RSV: respiratory syncytial virus

TSB: total bilirubin

WBC: white blood cell count

\section{Declarations}

\section{Funding}

None

\section{Competing Interests:}

The authors declare that the research was conducted in the absence of any commercial or financial relationships that could be construed as a potential conflict of interest.

Availability of data and material:

The data sets analyzed during the current study are available from the corresponding author on reasonable request.

\section{Code availability:}

Not applicable.

\section{Authors' Contributions:}

Liu Jie, Sun DanYan and Pang YuSheng:conceptualization. Liu Jie, Qin SuYuan and Ying BingBing: formal analysis. Su DanYan and Wang BaoFeng:methodology. Liu Jie and Qin SuYuan: writing-original draft. Liu Jie and Pang YuSheng: writing-review and editing. All authors approved the final manuscript as submitted and agree to be accountable for all aspects of the work.

\section{Ethics approval:}

Approval for this research was required from the Medical Ethic Committee of the First Affiliated Hospital of GuangXi Medical University(Code number;2021(KYE-240)).

\section{Consent to participate:}

Informed consent was obtained from all individual participants included in the study. 
Consent for publication:

This manuscript is not under simultaneous consideration by any other publication. All authors have approved the final manuscript and take full responsibility for the manuscript.

\section{References}

1. McCrindle BW, Manlhiot C (2020) SARS-CoV-2-Related Inflammatory Multisystem Syndrome in Children: Different or Shared Etiology and Pathophysiology as Kawasaki Disease? JAMA 324:246-248. https://doi.org/10.1001/jama.2020.10370

2. Whittaker E, Bamford A, Kenny J, Kaforou M, Jones CE, Shah P, Ramnarayan P, Fraisse A, Miller O, Davies P, Kucera F, Brierley J, McDougall M, Carter M, Tremoulet A, Shimizu C, Herberg J, Burns JC, Lyall H, Levin M, Group P-TS, Euclids, Consortia P (2020) Clinical Characteristics of 58 Children With a Pediatric Inflammatory Multisystem Syndrome Temporally Associated With SARS-CoV-2. JAMA 324:259-269. https://doi.org/10.1001/jama.2020.10369

3. Rife E, Gedalia A (2020) Kawasaki Disease: an Update. Curr Rheumatol Rep 22:75. https://doi.org/10.1007/s11926-020-00941-4

4. Burns JC, Glodé MP (2004) Kawasaki syndrome. Lancet 364:533-544. https://doi.org/10.1016/S0140-6736(04)16814-1

5. Principi N, Rigante D, Esposito S (2013) The role of infection in Kawasaki syndrome. J Infect 67:1-10. https://doi.org/10.1016/j.jinf.2013.04.004

6. Kim GB, Park S, Kwon BS, Han JW, Park YW, Hong YM (2014) Evaluation of the Temporal Association between Kawasaki Disease and Viral Infections in South Korea. Korean Circ J 44:250-254. https://doi.org/10.4070/kcj.2014.44.4.250

7. Morita A, Imada Y, Igarashi H, Yutsudo T (1997) Serologic evidence that streptococcal superantigens are not involved in the pathogenesis of Kawasaki disease. Microbiol Immunol 41:895-900. https://doi.org/10.1111/j.1348-0421.1997.tb01947.x

8. Hall M, Hoyt L, Ferrieri P, Schlievert PM, Jenson HB (1999) Kawasaki syndrome-like illness associated with infection caused by enterotoxin B-secreting Staphylococcus aureus. Clin Infect Dis 29:586-589. https://doi.org/10.1086/598638

9. Konishi N, Baba K, Abe J, Maruko T, Waki K, Takeda N, Tanaka M (1997) A case of Kawasaki disease with coronary artery aneurysms documenting Yersinia pseudotuberculosis infection. Acta Paediatr 86:661-664. https://doi.org/10.1111/j.1651-2227.1997.tb08952.x

10. Ferwerda A, Moll HA, de Groot R (2001) Respiratory tract infections by Mycoplasma pneumoniae in children: a review of diagnostic and therapeutic measures. Eur J Pediatr 160:483-491. https://doi.org/10.1007/s004310100775

11. Chua PK, Nerurkar VR, Yu Q, Woodward CL, Melish ME, Yanagihara R (2000) Lack of association between Kawasaki syndrome and infection with parvovirus B19, human herpesvirus 8, TT virus, GB virus C/hepatitis G virus or Chlamydia pneumoniae. Pediatr Infect Dis J 19:477-479.

https://doi.org/10.1097/00006454-200005000-00019

12. Kuijpers TW, Herweijer TJ, Schölvinck L, Wertheim-Van Dillen PM, Van De Veer EM (2000) Kawasaki disease associated with measles virus infection in a monozygotic twin. Pediatr Infect Dis J 19:350-353. https://doi.org/10.1097/00006454-200004000-00018

13. Chang LY, Lu CY, Shao PL, Lee PI, Lin MT, Fan TY, Cheng AL, Lee WL, Hu JJ, Yeh SJ, Chang CC, Chiang BL, Wu MH, Huang LM (2014) Viral infections associated with Kawasaki disease. J Formos Med Assoc 113:148-154. https://doi.org/10.1016/j.jfma.2013.12.008

14. Benseler SM, McCrindle BW, Silverman ED, Tyrrell PN, Wong J, Yeung RS (2005) Infections and Kawasaki disease: implications for coronary artery outcome. Pediatrics 116:e760-766. https://doi.org/10.1542/peds.2005-0559

15. Baker AL, Lu M, Minich LL, Atz AM, Klein GL, Korsin R, Lambert L, Li JS, Mason W, Radojewski E, Vetter VL, Newburger JW, Pediatric Heart Network I (2009) Associated symptoms in the ten days before diagnosis of Kawasaki disease. J Pediatr 154:592-595e592. https://doi.org/10.1016/j.jpeds.2008.10.006

16. Turnier JL, Anderson MS, Heizer HR, Jone PN, Glodé MP, Dominguez SR (2015) Concurrent Respiratory Viruses and Kawasaki Disease. Pediatrics 136:e609-614. https://doi.org/10.1542/peds.2015-0950

17. Dionne A, Le CK, Poupart S, Autmizguine J, Meloche-Dumas L, Turgeon J, Fournier A, Dahdah N (2018) Profile of resistance to IVIG treatment in patients with Kawasaki disease and concomitant infection. PLoS ONE 13:e0206001. https://doi.org/10.1371/journal.pone.0206001

18. Jordan-Villegas A, Chang ML, Ramilo O, Mejías A (2010) Concomitant respiratory viral infections in children with Kawasaki disease. Pediatr Infect Dis J 29:770-772. https://doi.org/10.1097/INF.0b013e3181dba70b

19. Kobayashi T, Ayusawa M, Suzuki H, Abe J, Ito S, Kato T et al (2020) Revision of diagnostic guidelines for Kawasaki disease (6th revised edition). Pediatr Int. 6th rev. ed. 62:1135-8. https//doi.org/10.1111/ped.14326

20. Fukazawa R, Kobayashi J, Ayusawa M, Hamada H, Miura M, Mitani Y, Tsuda E, Nakajima H, Matsuura H, Ikeda K, Nishigaki K, Suzuki H, Takahashi K, Suda K, Kamiyama H, Onouchi Y, Kobayashi T, Yokoi H, Sakamoto K, Ochi M, Kitamura S, Hamaoka K, Senzaki H, Kimura T Japanese Circulation Society Joint Working G (2020) JCS/JSCS 2020 Guideline on Diagnosis and Management of Cardiovascular Sequelae in Kawasaki Disease.Circ J84:1348-1407. https://doi.org/10.1253/circj.CJ-19-1094

21. McCrindle BW, Rowley AH, Newburger JW, Burns JC, Bolger AF, Gewitz M, Baker AL, Jackson MA, Takahashi M, Shah PB, Kobayashi T, Wu MH, Saji TT, Pahl E, American Heart Association Rheumatic Fever E, Kawasaki Disease Committee of the Council on Cardiovascular Disease in the Y, Council on C, Stroke N (2017) Council on Cardiovascular S, Anesthesia, and Council on E, Prevention Diagnosis, Treatment, and Long-Term Management of Kawasaki Disease: A Scientific Statement for Health Professionals From the American Heart Association. Circulation 135:e927-e999. https://doi.org/10.1161/CIR.0000000000000484

22. Tse SM, Silverman ED, McCrindle BW, Yeung RS (2002) Early treatment with intravenous immunoglobulin in patients with Kawasaki disease. J Pediatr 140:450-455. https://doi.org/10.1067/mpd.2002.122469

23. Wilson N, Heaton P, Calder L, Nicholson R, Stables S, Gavin R (2004) Kawasaki disease with severe cardiac sequelae: lessons from recent New Zealand experience. J Paediatr Child Health 40:524-529. https://doi.org/10.1111/j.1440-1754.2004.00456.x

Page $11 / 18$ 
24. Park HR, Han MY, Yoon KL, Cha SH, Moon SK, Jung HW (2017) Mycoplasma Infection as a cause of Persistent Fever after Intravenous Immunoglobulin Treatment of Patients with Kawasaki Disease: Frequency and Clinical Impact. Infect Chemother 49:38-43. https://doi.org/10.3947/ic.2017.49.1.38

25. Lee MN, Cha JH, Ahn HM, Yoo JH, Kim HS, Sohn S, Hong YM (2011) Mycoplasma pneumoniae infection in patients with Kawasaki disease. Korean J Pediatr 54:123-127. https://doi.org/10.3345/kjp.2011.54.3.123

26. Lan Y, Li S, Yang D, Zhou J, Wang Y, Wang J, Xu Y, Chen Z (2020) Clinical characteristics of Kawasaki disease complicated with Mycoplasma pneumoniae pneumonia: A retrospective study. Med (Baltim) 99:e19987. https://doi.org/10.1097/MD.0000000000019987

27. Dionne A, Ibrahim R, Gebhard C, Bakloul M, Selly JB, Leye M, Déry J, Lapierre C, Girard P, Fournier A, Dahdah N (2015) Coronary Wall Structural Changes in Patients With Kawasaki Disease: New Insights From Optical Coherence Tomography (OCT). J Am Heart Assoc 4. https://doi.org/10.1161/JAHA.115.001939

28. Maric LS, Knezovic I, Papic N, Mise B, Roglic S, Markovinovic L, Tesovic G (2015) Risk factors for coronary artery abnormalities in children with Kawasaki disease: a 10-year experience. Rheumatol Int 35:1053-1058. https://doi.org/10.1007/s00296-014-3186-9

29. McCrindle BW, Harris KC (2018) Coronary Artery Aneurysms After Kawasaki Disease: Understanding the Pathology. Can J Cardiol 34:1094-1097. https://doi.org/10.1016/j.cjca.2018.07.412

30. Ram Krishna M, Sundaram B, Dhanalakshmi K (2014) Predictors of coronary artery aneurysms in Kawasaki disease. Clin Pediatr (Phila) $53: 561-565$. https://doi.org/10.1177/0009922814530802

31. Guo C, Tan C, Xia X, Yuan Y, Zhao M, Yuan Z, Wang Y, Deng Z, Chen J, Zhou Y, Huang Y (2020) Tumour necrosis factor-a and myoglobin associated with the recovery time of coronary artery lesions in Kawasaki disease patients. J Paediatr Child Health 56:1382-1387. https://doi.org/10.1111/jpc.14942

32. Akagi T, Rose V, Benson LN, Newman A, Freedom RM (1992) Outcome of coronary artery aneurysms after Kawasaki disease. J Pediatr 121:689-694. https://doi.org/10.1016/s0022-3476(05)81894-3

33. Beitzke A, Zobel G (1989) Coronary aneurysm in Kawasaki syndrome: incidence and prognosis. Klin Padiatr 201:33-39. https://doi.org/10.1055/s-20071025272

34. Newburger JW, Takahashi M, Gerber MA, Gewitz MH, Tani LY, Burns JC, Shulman ST, Bolger AF, Ferrieri P, Baltimore RS, Wilson WR, Baddour LM, Levison ME, Pallasch TJ, Falace DA, Taubert KA, Committee on Rheumatic Fever E, Kawasaki D, American Heart A, American Academy of P (2004) Diagnosis, treatment, and long-term management of Kawasaki disease: a statement for health professionals from the Committee on Rheumatic Fever, Endocarditis and Kawasaki Disease, Council on Cardiovascular Disease in the Young, American Heart Association. Circulation 110:2747-2771. https://doi.org/10.1161/01.CIR.0000145143.19711.78

35. Fujiwara T, Fujiwara H, Hamashima Y (1987) Size of coronary aneurysm as a determinant factor of the prognosis in Kawasaki disease: clinicopathologic study of coronary aneurysms. Prog Clin Biol Res 250:519-520 PMID:3423060

36. Takahashi M, Mason W, Lewis AB (1987) Regression of coronary aneurysms in patients with Kawasaki syndrome. Circulation 75:387-394. https://doi.org/10.1161/01.cir.75.2.387

37. Mitani Y, Tsuda E, Kato H, Higaki T, Fujiwara M, Ogawa S, Satoh F, Nakamura Y, Takahashi K, Ayusawa M, Kobayashi T, Ichida F, Matsushima M, Kamada M, Suda K, Ohashi H, Sawada H, Komatsu T, Waki K, Shinoda M, Tsunoda R, Yokoi H, Hamaoka K (2019) Emergence and Characterization of Acute Coronary Syndrome in Adults After Confirmed or Missed History of Kawasaki Disease in Japan: A Japanese Nationwide Survey. Front Pediatr 7:275. https://doi.org/10.3389/fped.2019.00275

38. Tsuda E, Kamiya T, Ono Y, Kimura K, Kurosaki K, Echigo S (2005) Incidence of stenotic lesions predicted by acute phase changes in coronary arterial diameter during Kawasaki disease. Pediatr Cardiol 26:73-79. https://doi.org/10.1007/s00246-004-0698-1

39. Friedman KG, Gauvreau K, Hamaoka-Okamoto A, Tang A, Berry E, Tremoulet AH, Mahavadi VS, Baker A, deFerranti SD, Fulton DR, Burns JC, Newburger JW (2016) Coronary Artery Aneurysms in Kawasaki Disease: Risk Factors for Progressive Disease and Adverse Cardiac Events in the US Population. J Am Heart Assoc 5. https://doi.org/10.1161/JAHA.116.003289

40. Son MBF, Gauvreau K, Tremoulet AH, Lo M, Baker AL, de Ferranti S, Dedeoglu F, Sundel RP, Friedman KG, Burns JC, Newburger JW (2019) Risk Model Development and Validation for Prediction of Coronary Artery Aneurysms in Kawasaki Disease in a North American Population. J Am Heart Assoc 8:e011319. https://doi.org/10.1161/JAHA.118.011319

\section{Tables}

Table 1 Comparison of baseline characteristics between coronary artery aneurysm with and without infections 


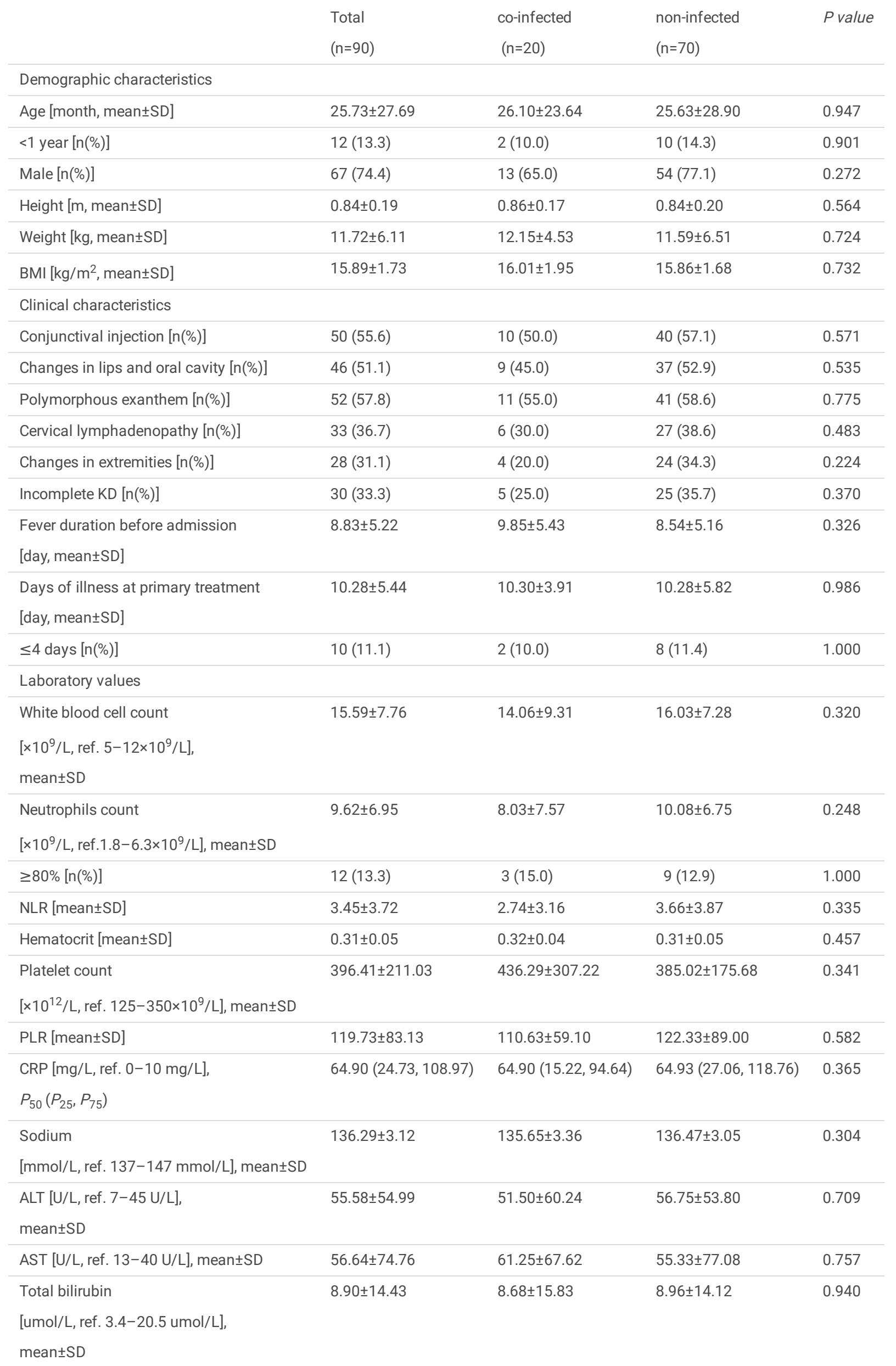




\begin{tabular}{lllll} 
Albumin [g/L, ref. $40-55 \mathrm{~g} / \mathrm{L}]$, mean \pm SD & $35.53 \pm 5.71$ & $34.51 \pm 5.13$ & $35.82 \pm 5.87$ & 0.367 \\
\hline CRP/ALB ratio $\left[P_{50}\left(P_{25}, P_{75}\right)\right]$ & $1.86(0.72,3.32)$ & $2.16(0.42,2.86)$ & $1.75(0.79,4.18)$ & 0.547 \\
\hline Clinical outcomes & & & & $5(7.1)$ \\
\hline PICU admission [n(\%)] & $6(6.7)$ & $1(5.0)$ & $12(17.1)$ & 0.062 \\
\hline IVIG resistance [n(\%)] & $20(22.2)$ & $8(40.0)$ & $5(7.1)$ & 0.205 \\
\hline Corticosteroid therapy [n(\%)] & $9(10.0)$ & $4(20.0)$ & $7(10.0)$ & 0.414 \\
\hline Thrombosis [n(\%)] & $11(12.2)$ & $4(20.0)$ & $3.74 \pm 1.18$ & 0.456 \\
\hline Baseline $Z$ score of coronary artery internal diameter & $3.79 \pm 1.22$ & $3.97 \pm 1.37$ & $3.28 \pm 1.33$ & 0.155 \\
\hline Left main coronary artery [mean $\pm S D]$ & $3.39 \pm 1.39$ & $3.78 \pm 1.56$ & $4.02 \pm 1.08$ & 0.285
\end{tabular}

BMI body mass index, KD Kawasaki disease, NLR neutrophil-to-lymphocyte count ratio, PLR platelet-to-lymphocyte count ratio, CRP C-reactive protein, ALT alanine aminotransferase, AST aspartate aminotransferase, CRP/ALB C-reactive protein-to-albumin, PICU pediatric intensive care unit, IVIG intravenous immunoglobulin, CAA coronary artery aneurysm.

Table 2 Comparison of baseline characteristics between coronary artery aneurysm with and without recovery 
Within 1 year

with recovery
$(n=57)$
$P$

without

recovery $(n=28)$
Within 2 years

with recovery $(n=73)$

Demographic characteristics

\begin{tabular}{|c|c|c|c|c|c|c|}
\hline Age [month] & $20.00(10.50,32.50)$ & $14.50(8.00,34.25)$ & 0.531 & $16.00(9.50,29.50)$ & $28.50(8.75,82.50)$ & 0.167 \\
\hline$<1$ year $[\mathrm{n}(\%)]$ & $5(8.8)$ & $6(21.4)$ & 0.197 & $10(13.7)$ & $1(8.3)$ & 0.961 \\
\hline Male $[n(\%)]$ & $42(73.7)$ & $21(75.0)$ & 0.896 & $56(76.7)$ & $7(58.3)$ & 0.321 \\
\hline Height [m] & $0.83(0.73,0.92)$ & $0.79(0.70,0.97)$ & 0.819 & $0.79(0.71,0.92)$ & $0.91(0.73,1.24)$ & 0.110 \\
\hline Weight [kg] & $11.34 \pm 5.28$ & $12.80 \pm 7.89$ & 0.314 & $10.00(8.25,13.00)$ & $12.55(8.78,19.75)$ & 0.084 \\
\hline BMI $\left[\mathrm{kg} / \mathrm{m}^{2}\right]$ & $15.69 \pm 1.74$ & $16.04 \pm 1.62$ & 0.382 & $15.82 \pm 1.67$ & $15.72 \pm 1.96$ & 0.848 \\
\hline \multicolumn{7}{|l|}{ Clinical characteristics } \\
\hline Conjunctival injection [n(\%)] & $34(59.6)$ & $15(53.6)$ & 0.594 & $43(58.9)$ & $6(50.0)$ & 0.563 \\
\hline Changes in lips and oral cavity $[\mathrm{n}(\%)]$ & $29(50.9)$ & $14(50.0)$ & 0.939 & $38(52.1)$ & $5(41.7)$ & 0.505 \\
\hline Polymorphous exanthem [n(\%)] & $34(59.6)$ & $15(53.6)$ & 0.594 & $44(60.3)$ & $5(41.7)$ & 0.227 \\
\hline Cervical lymphadenopathy [n(\%)] & $20(35.1)$ & $11(39.3)$ & 0.705 & $25(34.2)$ & $6(50.0)$ & 0.467 \\
\hline Changes in extremities [n(\%)] & 19 (33.3) & $6(21.4)$ & 0.258 & $22(30.1)$ & $3(25.0)$ & 0.984 \\
\hline Incomplete KD [n(\%)] & $19(33.3)$ & $9(32.1)$ & 0.913 & $25(34.2)$ & $3(25.0)$ & 0.764 \\
\hline Fever duration before admission [day] & $7.00(5.00,10.00)$ & $8.50(6.00,14.00)$ & 0.107 & $7.00(5.00,10.50)$ & $9.50(7.25,17.75)$ & 0.032 \\
\hline Days of illness at primary treatment [day] & $9.51 \pm 4.98$ & $11.46 \pm 6.39$ & 0.126 & $9.78 \pm 5.30$ & $12.42 \pm 6.54$ & 0.126 \\
\hline$\leq 4$ days $[n(\%)]$ & $7(12.3)$ & $3(10.7)$ & 1.000 & $9(12.3)$ & $1(8.3)$ & 1.000 \\
\hline Co-infected [n(\%)] & $9(15.8)$ & $8(28.6)$ & 0.166 & $14(19.2)$ & $3(25.0)$ & 0.938 \\
\hline \multicolumn{7}{|l|}{ Laboratory values } \\
\hline $\begin{array}{l}\text { White blood cell count }\left[\times 10^{9} / \mathrm{L} \text {, ref. } 5-\right. \\
\left.12 \times 10^{9} / \mathrm{L}\right]\end{array}$ & $14.71(9.60,19.99)$ & $13.29(9.31,19.94)$ & 0.970 & $14.28(8.79,19.86)$ & $15.65(11.92,29.46)$ & 0.970 \\
\hline $\begin{array}{l}\text { Neutrophilscount }\left[\times 10^{9} / \mathrm{L} \text {, ref. } 1.8-\right. \\
\left.6.3 \times 10^{9} / \mathrm{L}\right]\end{array}$ & $9.10 \pm 5.94$ & $9.98 \pm 7.97$ & 0.570 & $8.00(4.08,12.88)$ & $8.91(5.20,23.46)$ & 0.207 \\
\hline$\geq 80 \%[n(\%)]$ & $7(12.3)$ & $4(14.3)$ & 1.000 & $9(12.3)$ & $2(16.7)$ & 1.000 \\
\hline NLR & $3.30 \pm 3.45$ & $3.90 \pm 4.42$ & 0.496 & $3.37 \pm 3.52$ & $4.29 \pm 5.22$ & 0.437 \\
\hline Hemoglobin [g/L, ref. $120-160 \mathrm{~g} / \mathrm{L}]$ & $106.57 \pm 16.13$ & $100.74 \pm 14.06$ & 0.107 & $104.68 \pm 15.84$ & $104.46 \pm 15.03$ & 0.964 \\
\hline$\leq 110 \mathrm{~g} / \mathrm{L}[\mathrm{n}(\%)]$ & $30(52.6)$ & $21(75.0)$ & 0.048 & $43(58.9)$ & $8(66.7)$ & 0.849 \\
\hline Platelet count $\left[\times 10^{12} / \mathrm{L}\right.$, ref. $125-$ & 322.50 & 421.25 & 0.007 & 347.00 & 406.00 & 0.113 \\
\hline $\left.350 \times 10^{9} / \mathrm{L}\right]$ & $(237.40,435.15)$ & $(300.30,613.28)$ & & $(243.00,451.25)$ & $(288.35,647.85)$ & \\
\hline PLR & $110.15 \pm 86.13$ & $141.18 \pm 81.24$ & 0.116 & $120.73 \pm 89.30$ & $118.18 \pm 58.32$ & 0.924 \\
\hline CRP $[\mathrm{mg} / \mathrm{L}$, ref. $0-10 \mathrm{mg} / \mathrm{L}]$ & $58.75(10.45,114.91)$ & $70.57(42.31,105.83)$ & 0.467 & $75.86 \pm 60.47$ & $79.51 \pm 55.66$ & 0.845 \\
\hline Sodium [mmol/L, ref. 137-147 mmol/L] & $136.14 \pm 3.03$ & $136.14 \pm 3.18$ & 0.996 & $136.09 \pm 3.21$ & $136.50 \pm 1.99$ & 0.670 \\
\hline ALT [U/L, ref. 7-45U/L] & $50.90 \pm 53.14$ & $62.94 \pm 61.09$ & 0.353 & $54.06 \pm 55.55$ & $59.77 \pm 59.61$ & 0.745 \\
\hline AST [U/L, ref. 13-40U/L] & $53.85 \pm 70.78$ & $66.38 \pm 88.20$ & 0.482 & $59.51 \pm 81.31$ & $48.63 \pm 38.48$ & 0.651 \\
\hline $\begin{array}{l}\text { Total bilirubin [umol/L, ref. 3.4- } \\
\text { 20.5umol/L] }\end{array}$ & $8.96 \pm 15.25$ & $9.38 \pm 14.12$ & 0.903 & $9.48 \pm 15.89$ & $6.80 \pm 3.74$ & 0.564 \\
\hline Albumin [g/L, ref. $40-55 \mathrm{~g} / \mathrm{L}]$ & $36.04 \pm 5.76$ & $34.75 \pm 5.82$ & 0.336 & $35.74 \pm 5.72$ & $34.85 \pm 6.33$ & 0.623 \\
\hline$\leq 34 \mathrm{~g} / \mathrm{L}[\mathrm{n}(\%)]$ & $16(28.1)$ & $15(53.6)$ & 0.022 & $24(32.9)$ & $7(58.3)$ & 0.169 \\
\hline CRP/ALB ratio & $2.27 \pm 2.03$ & $2.38 \pm 1.74$ & 0.795 & $2.28 \pm 1.91$ & $2.48 \pm 2.10$ & 0.734 \\
\hline \multicolumn{7}{|l|}{ Clinical outcomes } \\
\hline PICU admission [n(\%)] & $3(5.3)$ & $3(10.7)$ & 0.637 & $6(8.2)$ & $0(0.0)$ & 0.588 \\
\hline IVIG resistance [n(\%)] & $8(14.0)$ & $10(35.7)$ & 0.021 & $16(21.9)$ & $2(16.7)$ & 0.975 \\
\hline
\end{tabular}




\begin{tabular}{|c|c|c|c|c|c|c|}
\hline Corticosteroid therapy $[\mathrm{n}(\%)]$ & $2(3.5)$ & $5(17.9)$ & 0.065 & $6(8.2)$ & $1(8.3)$ & 1.000 \\
\hline Thrombosis [n(\%)] & $1(1.8)$ & $10(35.7)$ & $<0.001$ & $4(5.5)$ & $7(58.3)$ & $<0.00$ \\
\hline \multicolumn{7}{|c|}{$Z$ score of coronary artery internal diameter at 1 month after onset } \\
\hline Left main coronary artery & $2.60(2.29,3.13)$ & $4.66(3.39,5.82)$ & $<0.001$ & $3.05 \pm 1.12$ & $5.58 \pm 2.06$ & $<0.00$ \\
\hline Right coronary artery & $2.13(1.48,2.83)$ & $4.68(2.79,5.65)$ & $<0.001$ & $2.60(1.67,3.22)$ & $5.72(4.12,6.80)$ & $<0.00$ \\
\hline
\end{tabular}

BMI body mass index, KD Kawasaki disease, NLR neutrophil-to-lymphocyte count ratio, PLR platelet-to-lymphocyte count ratio, CRP C-reactive protein, ALT alanine aminotransferase, AST aspartate aminotransferase, CRP/ALB C-reactive protein-to-albumin, PICU pediatric intensive care unit, IVIG intravenous immunoglobulin, CAA coronary artery aneurysm.

Table 3 Results of logistic regression analyses of coronary artery aneurysm without recovery within 1 year

\begin{tabular}{|c|c|c|c|c|c|c|}
\hline \multirow[t]{2}{*}{ characteristic } & \multicolumn{2}{|l|}{ Univariable } & \multicolumn{2}{|l|}{ Multivariable } & \multicolumn{2}{|l|}{ Adjust $\#$} \\
\hline & odds ratio $(95 \% \mathrm{Cl})$ & $P$ value & odds ratio $(95 \% \mathrm{Cl})$ & $P$ value & odds ratio $(95 \% \mathrm{Cl})$ & $P$ value \\
\hline Hemoglobin $\leq 110 \mathrm{~g} / \mathrm{L}$ & $0.370(0.136-1.008)$ & 0.052 & $0.542(0.132-2.220)$ & 0.394 & $0.539(0.105-2.537)$ & 0.435 \\
\hline Platelet count & $1.004(1.001-1.006)$ & 0.010 & $1.002(0.998-1.005)$ & 0.260 & $1.002(0.998-1.006)$ & 0.283 \\
\hline Albumin $\leq 34 \mathrm{~g} / \mathrm{L}$ & $0.338(0.132-0.867)$ & 0.024 & $0.871(0.202-3.750)$ & 0.853 & $0.863(0.171-4.357)$ & 0.858 \\
\hline Z socre of right coronary artery & $2.760(1.739-4.379)$ & $<0.001$ & $2.091(1.211-3.610)$ & 0.008 & $2.076(1.180-3.650)$ & 0.011 \\
\hline
\end{tabular}

\#indicates a significant relationship after correction for age and sex, IVIG intravenous immunoglobulin.

Table 4 Results of logistic regression analyses of coronary artery aneurysm without recovery within 2 years

\begin{tabular}{lllllll} 
characteristic & Univariable & & Multivariable & & \multicolumn{2}{c}{ Adjust } \\
\cline { 2 - 6 } & odds ratio $(95 \% \mathrm{Cl})$ & $P$ value & odds ratio $(95 \% \mathrm{Cl})$ & $P$ value & odds ratio $(95 \% \mathrm{Cl})$ & $P$ value \\
\hline Fever duration before admission & $1.154(1.030-1.293)$ & 0.014 & $1.136(0.962-1.343)$ & 0.133 & $1.180(0.963-1.447)$ & 0.110 \\
\hline Z socre of left main coronary artery & $3.145(1.766-5.600)$ & $<0.001$ & $2.058(0.961-4.407)$ & 0.063 & $2.212(0.962-5.086)$ & 0.062 \\
\hline Z socre of right coronary artery & $3.191(1.776-5.735)$ & $<0.001$ & $2.257(1.085-4.696)$ & 0.029 & $3.072(1.133-8.330)$ & 0.027
\end{tabular}

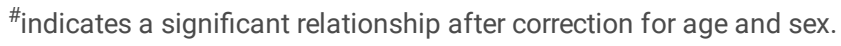

\section{Figures}



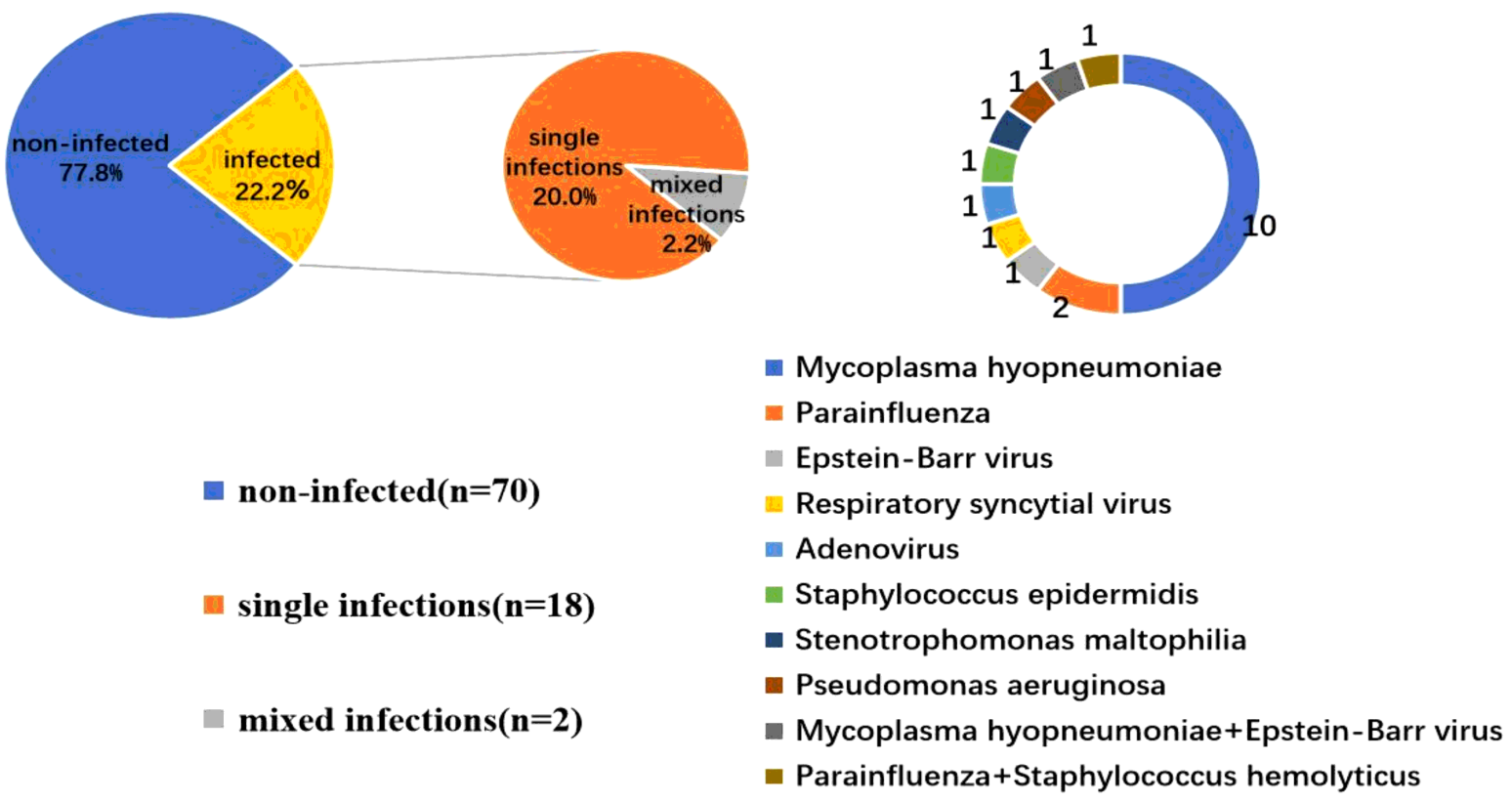

FIGURE 1 Distribution of pathogens in coronary artery aneurysm co-infection in Kawasaki disease

Figure 1

Distribution of pathogens in coronary artery aneurysm co-infection in Kawasaki disease

Figure 2

Coronary artery changes from baseline over time in Kawasaki disease patients with coronary artery aneurysm, by subgroups

CAA, coronary artery aneurysm. 


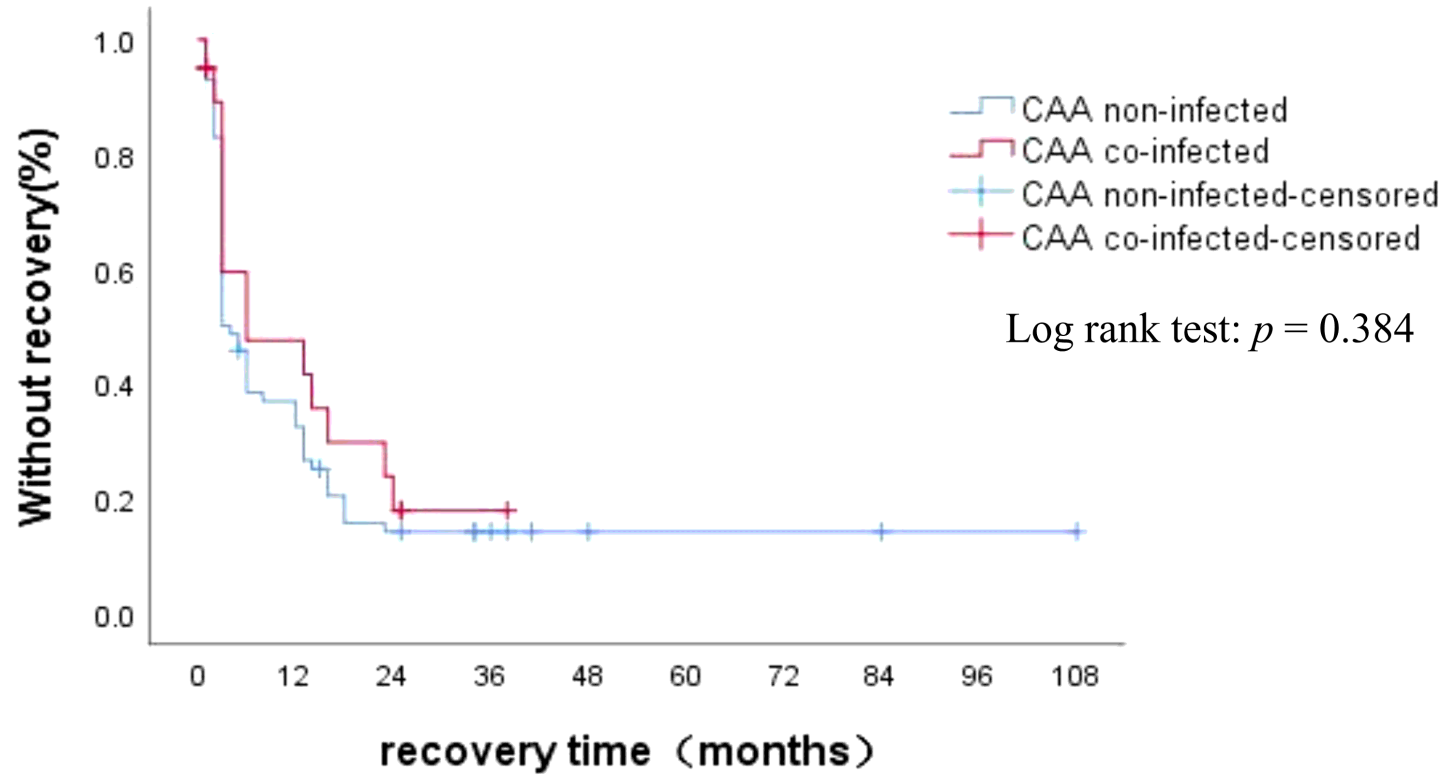

No at risk

$\begin{array}{lrrrrrrrrrr}\text { CAA co-infected } & 20 & 8 & 4 & 1 & 0 & 0 & 0 & 0 & 0 & 0 \\ \text { CAA non-infected } & 70 & 22 & 9 & 6 & 3 & 2 & 2 & 2 & 1 & 1\end{array}$

FIGURE 3 Kaplan-Meier comparative survival analysis of the time to coronary artery dilatation normalization

Figure 3

Kaplan-Meier comparative survival analysis of the time to coronary artery dilatation normalization

CAA, coronary artery aneurysm.

\section{Supplementary Files}

This is a list of supplementary files associated with this preprint. Click to download.

- supplementaryfile.docx 